\title{
Retorika I Dewa Made Rai Mesi dalam Pertunjukan Wayang Kulit Purwa Lakon Irawan Rabi
}

\author{
I Putu Ardiyasa \\ Jurusan Pedalangan, Institut Seni Indonesia Denpasar \\ Email: tuardiyasa@gmail.com
}

\begin{abstract}
Rai Mesi is an interesting phenomenon in the world of puppetry in Bali because its presence offers a different color and is able to revive the wayang kulit purwa. It is also what makes it a legendary dalang for the people. Rai Mesi as a dalang who is good at bringing stories, always be the first choice for people who want to hold a puppet show. Each show is always packed with spectators. It is therefore not surprising that the style of Rai Mesi puppetry is still used as a reference by the young puppeteers until now. Given its capacity as the mastermind of the story, the focus of the discussion in this paper is the issue of rhetoric that focuses on the choice of words, the use of language, and the way of narration, both in narrative and in dialogue. The data used is Lakon Irawan Rabi in the form of ribbon tape recordings which are then transcribed into written form. The result of the research shows that Rai Mesi has succeeded in composing the Irawan Rabi play as a Javanese wayang kulit playwoman to play Balinese parrot leather puppets through the processing of language style, both beautiful language, hilarious, figurative, and alternation. In addition to processing the style of language, Rai Mesi in his speech also inserted the language outside Bali, be it the language of the archipelago and foreign languages. Rai Mesi's rhetoric is very communicative.
\end{abstract}

Keywords: puppeteer; wayang; rhetoric; linguistic; vocabulary; narrative; impression

\begin{abstract}
Abstrak
Rai Mesi merupakan fenomena yang menarik dalam dunia pedalangan di Bali karena kehadirannya menawarkan warna yang berbeda dan mampu menggairahkan kembali pertunjukan wayang kulit purwa. Hal ini pula yang membuatnya menjadi dalang legendaris bagi masyarakatnya. Rai Mesi sebagai dalang yang pandai membawakan cerita, selalu menjadi pilihan pertama bagi masyarakat yang ingin menyelenggarakan pertunjukan wayang. Setiap pertunjukkannya selalu dipadati penonton. Oleh karena itu tidak mengherankan apabila gaya pedalangan Rai Mesi masih dijadikan acuan oleh dalang-dalang muda hingga sekarang. Mengingat kapasitasnya sebagai dalang cerita, maka fokus bahasan dalam tulisan ini adalah masalah retorika yang berfokus pada pemilihan kata, pemakaian bahasa, serta cara penuturannya, baik dalam narasi maupun dialognya. Data yang digunakan adalah Lakon Irawan Rabi dalam bentuk rekaman kaset pita yang kemudian ditranskrip ke dalam bentuk tulisan. Hasil penelitian menunjukkan bahwa Rai Mesi telah berhasil menggubah Lakon Irawan Rabi sebagai lakon wayang kulit Jawa menjadi lakon carangan wayang kulit parwa Bali melalui pengolahan gaya bahasa, baik bahasa indah, kocak, kiasan, dan alternasi.
\end{abstract}


Selain mengolah gaya bahasa, Rai Mesi dalam tuturannya juga menyisipkan bahasa luar Bali, baik itu bahasa Nusantara maupun bahasa asing. Retorika Rai Mesi sangat komunikatif.

Kata kunci: dalang; wayang retorika; kebahasaan; kosakata; penuturan; kesan

\section{Pendahuluan}

Tahun 1970-an, kehadiran Rai Mesi telah memberi warna baru serta menggairahkan kembali kehidupan pedalangan wayang kulit purwa di Bali. Frekuensi pertunjukan wayang kulit purwa mengalami peningkatan, dan tentunya Rai Mesi selalu menjadi prioritas utama dalam pemilihan dalang. Ketenarannya tidak hanya sebatas di lingkungannya, tetapi sampai ke luar daerah, bahkan hampir seluruh wilayah di Bali. Oleh karena itu sangat wajar apabila Rai Mesi hingga sekarang menjadi kiblat bagi dalang-dalang Bali generasi selanjutnya. Oleh masyarakat, Mesi dikenal sebagai dalang yang ahli dalam mengolah cerita. Lakon yang semula asing, setelah ditangan Mesi, menjadi lakon yang sangat populer. Contoh yang nyata adalah Lakon Irawan Rabi. Lakon ini adalah lakon wayang kulit purwa Jawa. Setelah diolah oleh Mesi, kemudian menjadi lakon yang sangat populer, bahkan seakan-akan telah menjadi lakon Bali, atau dikenal dengan istilah lakon carangan dalam wayang kulit Bali. Sebagaimana gelar yang diberikan masyarakat kepada Rai Mesi, yakni sebagai dalang cerita, maka dapat diasumsikan bahwa pengolahan pedalangan Rai Mesi bertumpu pada kekuatan retorikanya.

Retorika adalah salah satu unsur kebahasaan yang tidak pernah luput dari kehidupan bertutur manusia. Selama ada usaha orang berkomunikasi, terutama yang bertujuan untuk mempengaruhi orang lain, maka akan selalu ada dalam kegiatan bertutur, dan selama itu pula orang terlibat dengan masalah retorika. Goris Keraf menyatakan bahwa retorika adalah suatu teknik pemakaian bahasa sebagai seni baik tertulis maupun lisan, yang didasarkan pada suatu pengetahuan yang tersusun dengan baik (Keraf, 1985: 3). Retorika tulisan biasanya ada pada suatu karya sastra, salah satunya adalah naskah drama. Oka (dalam Rota, 1990: 17) menjelaskan bahwa retorika selalu ada dalam kehidupan bermasyarakat, dan orang tidak bisa menghindarkan dirinya dari masalah-masalah retorika selama dia bertutur. Artinya bahwa pemahaman retorika di sini lebih diorientasikan pada penuturan lisan atau bentuk verbal. Berdasarkan pandangan dua tokoh di atas maka dapat diambil pemahaman bahwa dua aspek yang harus diketahui dalam retorika adalah pertama, pengetahuan mengenai retorika; kedua adalah cara penggunaan bahasa dengan baik. Mengingat bahwa aspek verbal sangat sulit ditransfer dalam bentuk tulisan, seandainya dipaksa pun tentu akan terlalu banyak suprasekmental yang hilang, maka bahasan dalam tulisan ini lebih berfokus pada retorika yang berbentuk naskah pakem (tulisan) wayang kulit parwa. Namun demikian, sebagaimana kapasitas penulis sebagai pecinta dan pemerhati pertunjukan Rai Mesi, tentunya penjelasan di sini sangat dipengaruhi oleh aspek verbal sebagaimana yang terjadi dalam pertunjukan langsungnya.

Pertunjukan wayang kulit purwa tradisi Bali, sebagai drama konvensional, persoalan retorika ini pada dasarnya dapat dikelompokkan menjadi dua kategori, yaitu retorika pakem dan retorika tidak pakem. Yang dimaksud retorika pakem adalah retorika yang pola dan penggunaan bahasanya sudah diikat oleh kaidah konvensional; sedangkan yang tidak pakem adalah retorika yang memiliki ruang kebebasan. Retorika pakem pada umumnya diberlakukan pada tokoh-tokoh dewa, brahmana, dan ksatria; sedangkan retorika tidak pakem diberlakukan pada tokoh panakawan. Meskipun retorika tidak pakem, tetapi harus direncanakan dengan baik dan intensif agar komunikatif sehingga mampu memancing peran serta penonton sebagai bagian dari pertunjukan wayang itu. $\mathrm{Hal}$ ini penting karena dalam pertunjukan wayang kulit, tokoh panakawan memiliki ruang khusus untuk menyampaikan berbagai informasi serta kepentingan khusus, baik bagi si dalang, penanggap, maupun pemerintah. Oleh karena itu seorang dalang harus memiliki kecakapan bertutur dengan unsur-unsur retorik yang terencana dan terarah 
agar menarik penonton. Hal ini penting karena pada dasarnya isi cerita yang dipaparkan dalam pertunjukan wayang kulit sudah dipahami dengan baik oleh penontonnya (Darma, 1983: 7). Dengan demikian, dapat dikatakan bahwa kemampuan retorika seorang dalang sangat menentukan sukses atau tidaknya suatu pertunjukan wayang (periksa Purnamawati, 1997: 11).

Mengingat bahwa keberadaan retorika dalam pertunjukan wayang kulit merupakan hal yang sangat penting, maka peneliti tertarik untuk mengkaji tentang retorika dalam Lakon Irawan Rabi yang dipergelarkan oleh dalang Rai Mesi. Oleh karena peneliti merupakan insider, sebagai bagian dari masyarakat pedalangan Bali dan pemerhati dalang Rai Mesi, maka meskipun data utama berbentuk transkrip pertunjukan dirasa tetap bisa mewakili karena dengan mendengarkan, peneliti mampu membayangkan semua peristiwa yang terjadi dalam pertunjukan (Wahyudi, 2012: 36). Melalui mendengarkan itu pula peneliti bisa mengidentifikasi aspek retorikanya. Meskipun demikian, mengingat bahwa aspek dalam retorika itu sangat kompleks dan tidak semuanya dapat ditransformasikan ke dalam bentuk tulisan, maka dalam artikel ini hanya difokuskan pada persoalan yang bisa dijelaskan melalui bahasa tulis. Oleh karena itu ada dua permasalahan yang ingin diungkapkan dalam artikel ini (1) mengenai bagaimana aspek-aspek kebahasaan dalam Lakon Irawan Rabi; (2) bagaimana cara penyajian tuturnya. Kata, kelompok kata atau kalimat dalam Lakon Irawan Rabi ini ditata sedemikian rupa sesuai dengan aturan yang sudah berlaku. Seperti penggunaan tata bahasa Bali, penempatan materi bahasa, yang ditata berdasarkan corak bahasa kemudian disajikan dengan gaya bahasa yang sudah ditentukan berdasarkan aturan (pakem) yang mengikatnya. Korzybski dalam buku Retorika Dalam Prakteknya mengatakan bahwa retorika lebih banyak memberikan bimbingan tetang cara memanfaatkan bahasa dalam kegiatan bertuturnya, antara lain: (1) Memilih Materi Bahasa; (2) Menata Materi Bahasa; (3) Memilih Corak Bahasa; dan (4) Memilih Gaya Bahasa. Oleh karena itu, empat persoalan itulah yang dijadikan konsentrasi dalam usaha memahami aspek-aspek retorika Lakon Irawan Rabi dalam wayang kulit parwa (selanjutnya disingkat WKP) dalang Rai Mesi.

\section{Aspek Kebahasaan}

Berikut ini merupakan pelacakan dan pembicaraan tentang aspek-aspek kebahasaan dalam Lakon Irawan Rabi yang dibawakan oleh Rai Mesi.

\section{Pemilihan Materi Bahasa}

Pemilihan materi bahasa dalam hal ini adalah cara kecakapan dalang Rai Mesi dalam memilih kata, ungkapan, dan istilah lain dalam pergelaran wayang. Dalam hal ini, pemilihan materi bahasa didasarkan atas penyesuaian yang tepat dengan situasi tutur, topik tutur, kondisi tutur, dan sebagainya. Pertunjukan wayang kulit Bali, khususnya WKP pada dasarnya hanya menggunakan dua bahasa, yaitu bahasa kawi dan bahasa Bali. Namun demikian, dalam hal tertentu, untuk mengejar efektivitas, dalang sering kali menyisipkan bahasa Indonesia, bahkan bahasa Inggris.

Dalam Lakon Irawan Rabi, dalang Rai Mesi betul-betul menggunakan berbagai cara dalam usahanya memanfaatkan potensi bahasa (terutama bahasa Bali) dalam memenuhi penyajian tutur yang efektif. Ketepatan memilih materi bahasa di dalam segala situasi, kondisi dapat dilihat pada dialogdialog pada setiap pembabakan. Seperti pada Lakon Irawan Rabi babak II, adegan saat Irawan bertemu dengan panyeroan Diah Lismaya Wati, nampak jelas kegunaannya dalam pembicaraan masalah asmara (roman). Kata-kata, ungkapan, dan istilah yang dipakai oleh tokoh Diah Lismaya Wati sangat tepat sesuai dengan adegan romantis. Ungkapan di atas dapat dilihat pada kutipan dialog di bawah: Diah Lismaya Wati: Uduh paliwari, ingulun tan sida tinolih ikanang wang, lwir kadi sang hyang Semara rupanya. kadiang apa atangiaatangia kalaganta paliwara. (keluar kelir)

Irawan : Menawa wuwus tinibakaken lawan watran sang hyang Semara.

Tualen : Kene panah sang hyang Semara nika, ngeruduh nasne. Jeg jengah bene. (kaset II, side A 437-440)

Percakapan di atas menunjukan bahwa pemilihan kata "lwir kadi Sang Hyang Semara" dipilih untuk melukiskan bahwa wajah Irawan sangat tampan dan parasnya bersinar. Penekanan bahasanya terletak pada kata sang hyang Semara dan pada kata lwir kadi intonasinya diperjelas dan penuh penekanan serta semara diperpanjang pada huruf 
akhirnya menjadi Semaraaa. Pemilihan kata dan ungkapan dalam dialog di atas tampak sebagai upaya untuk memenuhi kebutuhan masyarakat pemakai dan penikmatnya, yaitu masyarakat pendukung pedalangan Rai Mesi. Hal demikian tentu akan berbeda apabila pergelaran tersebut berada di luar wilayah pendukung Rai Mesi, tentu akan memiliki implikasi yang berbeda. Dengan demikian, pemilihan kata dan ungkapan yang bagus saja tidaklah cukup apabila tanpa memperhatikan tempat, situasi, dan kondisi pertunjukan tersebut (Purnamawati, 1997: 13). Artinya bahwa bahasa yang bagus belum tentu efektif. Oleh karena itu, agar menjadi efektif, maka dalam pemilihan materi bahasa haruslah mewadahi gagasan yang dimaksud penutur serta mampu mengungkapkan kembali gagasan tersebut kepada audien (periksa Purnamawati: 1997: 13).

Berkenaan dengan tuntutan di atas, ruang yang leluasa untuk melakukan pemilihan diksi agar sesuai dalam segala situasi adalah adegan punakawan. Hal demikian dapat dilihat pada Lakon Irawan Rabi pada babak ke II, saat Tualen memberikan tutur kepada Condong. Nampak jelas kegunaan materi bahasa dalam membicarakan masalah kewajiban wanita.

Condong: Napi punika arti wanitane?

Tualen : (bernyanyi) Darma sesana wanita ento incepang apang pasti, panca sila anggo dasar, eka ngaran warna luwih. Eka: abesik, ngaran: dadi, luwih: becik. Dadi ainak luh gobane pang jegeg. Dwi laksana ne becik. Dwi: dadua, laksanane becik. Tingkahe pang luwung dadi wanita. Tri kaya apang adung, Tri Kaya Parisudhane (kayika, wakcika, manahcika) to adungang buka telu. To anggo dasar. Catur ngaran satyeng laki. yen ragane ngelah anak muani, pang satya ngajak anak muani, yadiastun anak muani tiwas, bocok apan suba kadung mejangkepan apang satya ngayahin anak muani. Yen ngelah anak muani dadi pegawai awake jumah nyakan. Teka anake muani uli kantor sube natepatang baas lebeng. Sing nasi ne lebeng. Yen ngelah anak muani dadi petani, awake jumah nyakan. Teka anake muani uli carik pang sube napetang baas lebeng.
Pang sing, anake muani ngajakang ke uma, awake jumah ngajakang megae. (kaset seri II, side A, 485-488)

Dialog Tualen di atas menjelaskan mengenai arti wanita serta kewajibannya. Wanita harus berani membela diri demi kebenaran. Wanita harus satyeng laki yang artinya setia kepada satu laki-laki. Yang menarik dari dalang Rai Mesi dalam mengulas arti "wanita" tersebut adalah dengan memadukan antara bentuk tembang dan dialog biasa. Hal demikian membuat dialog tersebut terkesan unik dan enak didengar. Terlebih lagi dalam penyampaiannya ditunjang dengan kemampuan tembang yang baik, sehingga penikmat mampu memberi tanggapan atas gagasan yang dimaksudkan dalang.

Kedua kutipan dialog di atas, berdasarkan konteksnya menunjukkan adanya perbedaan. Dialog pertama menunjukkan konteksnya dengan lakon dan tokohnya; sedangkan dialog kedua, selain konteks dengan lakon, tetapi bisa juga dalam konteks masyarakatnya. Materi dialog yang demikianlah yang dikatakan sebagai ungkapan yang sesuai dengan segala situasi. Persoalan tentang hak dan kewajiban seorang wanita seperti yang tercantum dalam potongan kalimat "darma sesana wanita ento tincepang apang pasti, panca sila anggo dasar, eka ngaran warna luwih" merupakan pemahaman umum yang berlaku pula dalam realitas kehidupan sehari-hari. Wanita harus berperilaku baik dengan berdasarkan lima hal, yang pertama adalah paras yang menarik. Dengan penyampaian dalam bentuk tembang, pesan sang dalang tersebut mampu memberikan kesan tersendiri kepada penikmatnya.

\section{Pemilihan Ragam Bahasa}

Sastra dalam dunia pewayangan termasuk pula dalam Lakon Irawan Rabi ini, memiliki berbagai macam ragam bahasa, yang penggunaannya diatur dalam kaidah konvensional sesuai dengan bidang masing-masing ragam bahasa. Bahasa formal lebih tepat digunakan untuk acara resmi, seperti adegan persidangan. Sedangkan ragam bahasa non formal atau pergaulan, seyogyanya digunakan untuk acara tidak resmi atau dalam pergaulan biasa. Hal ini penting karena apabila untuk adegan resmi digunakan bahasa pergaulan akan memberikan kesan bahwa dalang tidak menguasai kaidah bahasa, serta akan menimbulkan kesan tidak adanya tata krama. Sebaliknya, apabila dalam situasi santai yang 
tidak resmi digunakan bahasa formal, maka dialog akan terkesan kaku dan tidak hidup; bahkan dapat menimbulkan kesan bahwa sang dalang hanya hafalan saja. Dengan demikian pemilihan ragam bahasa dalam retorika pedalangan adalah pemilihan kata yang tepat agar sesuai dengan situasi, kondisi tutur, bentuk tutur, topik tutur, kondisi penanggap tutur, serta lingkungan sosoial dan budayanya. Hal demikianlah yang dikatakan bahwa dalang mampu memilih dan menggunakan bahasa yang efektif.

Salah satu contoh pemilihan ragam bahasa yang terdapat dalam Lakon Irawan Rabi adalah dialog antara Anoman dan Tualen dalam adegan perjalanan menuju ke Astina, saat Anoman mengantar Irawan menuju ke Astina untuk menculik Diah Lismaya Wati. Keduanya berbahasa sesuai dengan situasi, kondisi yang tidak resmi. Oleh karena keberadaannya tidak dalam persidangan dan bahkan di luar kerajaan, maka dialognya digunakan bahasa tidak resmi. Hal ini dapat dilihat pada kutipan dialog di bawah ini.

Tualen : Inggih pang taen mekeber acepok.

Anoman : (Angkat-angkatan) akinkin yata lumaris. Sigraaa, bwahhhh, ahbhhh bwahhhh

Tualen : Owekkkk, owekkkk, owekkkk, mereren.... Anoman : Kadiang punapa?

Tualen : Pang engken iiratu mekeber misi nungkayak melingeb? Meadukan isisin basange?

Anoman : Udia kalaganta tiba?

Tualen : Ten je takut ulung. (kaset I, side A, 8591)

Bahasa tidak resmi pada dialog di atas tampak pada ungkapan yang dipakai oleh Tualen, yaitu "Pang engken iiratu mekeber misi nungkayak melingeb? Meadukan isisin basange?" (Kenapa kamu [Anoman] terbang dengan posisi bolakbalik badan?).

Fenomena di atas menjadi berbeda ketika dialog Anoman dengan Tualen terjadi dalam situasi yang bersifat fomal, yaitu adegan persidangan seperti dialog di bawah ini.

Tualen : (pengalang) Sawur ira tan apanjang, singgih sang nguniwara ulun yeki, ketalian dening bakti lawan asih. Uduhbh aratu dewa agung, mamitang lugra tityang parekan ituwa, matur tityang ring buk padan palungguh aratu, aratu sareng sami sane iring tityang sewewengkoning sabe mendala pandawa, pinih rihin aratu pangobaktin tityang katur ring palungguh arutu sareng sami mangdene sampun itua kecawaking ila kadi mangkin. Nunas lugra.

Anoman : Ngadeg...tualen kalaganta ya ta warian wus asung kerta lugraha juga lawan sira bayu temaja, mulih ring hyang-hyangin sinembah kalawan kita tualen. (kaset I, side A, 04-05)

Pernyataan Tualen kepada Anoman"Uduhhh aratu dewa agung, mamitang lugra tityang parekan ituwa, matur tityang ring buk padan palungguh aratu", menunjukkan bahwa Tualen sangat menghormati Anoman, hormat seorang abdi kepada tuannya, yang diungkapkan dalam bahasa formal. Dialog di atas menunjukkan bahwa ketika dalam adegan persidangan yang situasinya resmi, kalimat yang digunakan Tualen dalam dialog dengan Anoman berubah menjadi bahasa formal. Artinya bahwa dalam situasi resmi, maka seorang panakawan pun harus menggunakan ragam bahasa formal. Hal demikian menunjukkan bahwa dalang Rai Mesi mampu menggunakan bahasa yang efektif, yakni melakukan pemilihan ragam bahasa yang disesuaikan dengan situasi dan orang yang di ajak berkomunikasi (Periksa Purnamawati, 1997: 23).

\section{Memilih Gaya Bahasa}

Gaya bahasa adalah satu unsur yang memegang peranan paling penting dalam kegiatan bertutur. Goris Keraf (1981: 98-99) menyatakan bahwa gaya bahasa merupakan bagian dari pilihan kata-kata yang mempersoalkan sesuai dan tidaknya kata, frase atau subkalimat tertentu untuk menghadapi situasi yang tertentu pula. Lebih jauh Keraf (1981: 98-99) mengatakan bahwa gaya bahasa merupakan cara untuk mengungkapkan pikiran melaui bahasa secara khas yang memperlihatkan jiwa dan kepribadian penutur.

Hal lain yang termasuk dalam gaya bahasa (gaya bertutur) masyarakat pewayangan Bali adalah cara dalang mengungkapkan buah pikirannya melalui kalimat-kalimat yang khas, dan cara ia menyusun buah pikiran melalui berbagai bentuk komposisi tutur yang efektif dan menarik, serta mengandung nilai estetis. Kodi (wawancara, 12 Februari 2015) mengatakan bahwa bahasa yang digunakan para dalang di Bali pada masa lampau 
lebih banyak mengambil dari bahasa yang termuat dalam parwa-parwa. Hal demikian dikarenakan bahasa dalam parwa merupakan bahasa yang siap pakai, sehingga dengan mudah dalang menggunakannya. Pendapat tersebut di atas sesuai dengan pandangan I Wayan Kawen (Periksa Rota, 1990: 295) yang mengatakan bahwa para dalang harus mangda dedudonan lengkaran parwane tilad (meniru rangkaian kalimat-kalimat parwa).

Selain dari teks parwa, dalang juga banyak mengambil gaya bahasa dari kakawin, baik Kakawin Bratayuda, Kakawin Arjunawiwaha, Kakawin Ramayana, maupun yang lainnya, terutama dalam bentuk tutur bertembang. Zurbuchen (Periksa Rota, 1990: 296) mengasumsikan, bahwa kebiasaan menggunakan tembang-tembang (nyanyian-nyanyian) dalam pertunjukan wayang sudah berlaku sejak zama dahulu; bahkan dalam dialog wayang juga ditembangkan. Ini dapat dibuktikan dengan adanya pernyataan dalam Kakawin Ramayana yang menyebutkan "widu mewayang" yang artinya seorang penyanyi yang mempertunjukkan wayang.

Berdasarkan fakta yang termuat dalam teks rekaman kaset pita pertunjukan wayang kulit Rai Mesi menunjukkan bahwa tutur gaya selangseling (alternasi) sangat mendominasi rangkaian tutur pertunjukan wayangnya. Dengan pola penggunaan gaya tutur yang demikian, dirasa menjadi lebih efektif, indah, dan menarik di antara berbagai tutur yang disajikan. Jika semua tokoh wayang menggunakan bahasa kawi, nampak jelas pertunjukan tidak akan komunikatif karena tidak semua penikmat memahami bahasa kawi. Demikian juga apabila hanya menggunakan bahasa Bali, pertunjukan akan kehilangan keangkeran, dan kewibawaannya karena tidak ubahnya seperti pembicaraan sehari-hari. Selain gaya alternasi, masih ada lagi gaya bahasa yang lain dalam Lakon Irawan Rabi ini, seperti tutur bertembang, epentesis, koreksio, kontradiksio dan lain-lain.

\section{Menata Materi Bahasa}

Kata-kata, istilah, dan ungkapan-ungkapan yang telah dipilih oleh sang dalang perlu ditata dalam wujud tutur yang efektif. Katakata, istilah, dan ungkapan-ungkapan yang merupakan materi pokok bahasa dalam dunia pewayangan Bali, keberadaannya tidak akan bisa berbuat banyak kalau tidak ditata secara efektif (Rota, 1990: 293). Oleh karena itu tugas utama seorang dalang dalam beretorika adalah menata materi bahasa menjadi kalimat yang utuh, padu dan bervariasi, baik berkenaan dengan panjangpendek maupun struktur bahasanya. Berdasarkan persoalan demikian, penataan materi bahasa Lakon Irawan Rabi dalam WKP dapat diklasifikasikan menjadi tiga jenis, yaitu: dialog, narasi, dan tutur bertembang. Di antara kegita jenis tersebut, dialog merupakan persoalan yang paling dominan dari keseluruhan tutur. Adapun jenis dialog yang sudah ditata materinya menjadi sebuah kalimat yang utuh, padu, dan bervariasi, di antaranya adalah sebagai berikut.

Sangut : Inggihtitiang matur ring iratu. (kakawin) yan kewalang pandita totalanta, wimuda mati satru tanpa dosa; yan sesanan sang meraga wiku Sane marginin iratu, wimuda mati satru, belog san iratu ngematiang musuh, tanpa dosa: anak sing ngelah pelih bakat matiang.

Arjuna : Ulun tan harep amejahaken caraka (Arjuna keluar). (kaset III, side A, 947948)

Penataan materi bahasa dilakukan dengan memadukan unsur ungkapan, kata, dan kalimat yang di dalamnya terdapat dialog, narasi dan tutur bertembang. Seperti penuturan ungkapan "wimuda mati satru” dilafalkan dalam bentuk tembang, sedangkan perkataan selanjutnya "belog san iratu ngematiang musuh, tanpa dosa” tidak ditembangkan. Hal demikian bertujuan untuk memperkuat dan menegaskan makna dari kalimat sebelumnya, yang ditembangkan. Dengan cara demikian membuat isi yang terkadung dalam tutur tersebut lebih menarik dan komunikatif.

\section{Aspek Tuturan}

Berikut ini merupakan pelacakan dan pembicaraan tentang aspek tutur dalam Lakon Irawan Rabi yang dibawakan oleh Rai Mesi.

\section{a. Dialog}

Dialog merupakan proses komunikasi antar tokoh dalam bentuk bahasa verbal. Dalam tradisi pedalangan Bali, dialog tersebut memiliki kaidah-kaidah tertentu yang disesuaikan dengan strata sosial masing-masing tokoh. Tokoh-tokoh 
yang tergolong bangsawan pada umumnya menggunakan bahasa kawi, sedangkan tokoh panakawan menggunakan bahasa Bali. Dalam Lakon Irawan Rabi ini, tokoh yang menggunakan bahasa kawi, di antaranya adalah Irawan dan Anoman; sedangkan tokoh yang menggunakan bahasa Bali adalah para panakawan, yaitu Tualen dan Merdah. Berdasarkan hasil penelitian, penulis menemukan bahwa dalang Rai Mesi banyak memakai atau meniru bahasa yang terdapat dalam lontar Parwa. Jika dilihat dari aspek retorika maka dialog bahasa kawi di atas nampaknya tidak banyak memberikan peluang kepada dalang untuk berimprovisasi dengan menyajikan berbagai gaya bertutur seperti halnya dalam penggunaan dialog bahasa Baliyang dilakukan oleh tokoh panawakan. Berdasarkan pengamatan penulis dari Lakon Irawan Rabi yang dibawakan oleh Rai Mesi, dapat ditemukan gaya penyajian sebagai berikut.

\section{Gaya Alternasi}

Kreativitas Rai Mesi dalam membangun kombinasi berbagai materi bahasa tutur meliputi alternasi tutur berbahasa Bali dengan tutur berbahasa kawi, tutur ragam resmi dengan tutur ragam tidak resmi, tutur berirama panjang dengan tutur berirama pendek, serta antara tutur bertembang dengan gancaran atau prosa. Berikut akan dijelaskan serta diberikan contoh gaya alternasi yang dimaksud.

a) Alternasi bahasa Kawi dengan bahasa Bali

Gaya alternasi jenis ini ditemukan pada semua jenis pertunjukan wayang kulit tradisi Bali, khususnya WKP dalang Rai Mesi. Jenis gaya ini sering dipakai pada adegan petangkilan panakawan dengan junjungannya. Dalam hal ini adalah tokoh Irawan dengan Tualen. Berikut contoh kutipan dialog yang dimaksud.

Tualen: Inggih aratu dewa agung, sampun pisan sayaga tityang pacang nampa nyuwun pawecanan iratu.

Irawan: Enak kauntab tualen kalaganta rumenge pawarah paman bayu suta.

Tualen:iratu becikang nyen mirengang, pawecanan ida sang anoman, mangda sampun singsal daging pawecanane ring penampen aratu.

\section{Irawan : Kawingkin-kawingkin kalagant}

(kaset I, side A, 18-21)

Kutipan di atas menunjukkan bahwa tokoh panakawan Tualen memakai bahasa Bali pada saat berdialog dengan Irawan, sedangkan tokoh Irawan menggunakan bahasa kawi karena Irawan lebih tinggi kedudukannya. Kutipan ini terdapat pada adegan petangkilan pihak kanan. Dalam setiap adegan gaya alternasi jenis ini akan dipakai, kecuali adegan dialog panakawan dengan panakawan. Kutipan di atas, adalah salah satu dari beberapa alternasi jenis bahasa kawi dengan bahasa Bali yang terdapat di dalam naskah Lakon Irawan Rabi. Kutipan tersebut kiranya dapat memberikan gambaran tentang gaya yang dimaksud. Cara Rai Mesi tersebut menunjukkan konsistensinya terhadap kaidah pedalangan Bali bahwa tokoh bangsawan menggunakan bahasa kawi, sedangkan panakawan memiliki keleluasaan dalam penggunaan bahasa.

b) Alternasi ragam resmi dengan ragam akrab

Sebagaimana telah dipaparkan di depan bahwa tutur ragam resmi biasanya ditemukan pada dialog peguneman atau patangkilan antara tokoh para ratu. Hal demikian berlaku, baik untuk tokoh pihak kanan maupun pihak kiri. Yang termasuk pihak kanan, di antaranya adalah Irawan, Arjuna, Bima, Anoman, Yudistira dan golongannya; sedangkan pihak kiri di antaranya adalah Kala Nila Ludraka, Sakuni dan golongannya. Namun demikian kadangkadang diberlakukan pula pada dialog Irawan dengan Tualen, maupun Anoman dengan Merdah. Tutur ragam tidak resmi sering kali digunakan dalam suasana akrab, terutama dalam dialog antar panawakan sendiri, seperti dialog Tualen dengan Merdah maupun Delem dengan Sangut. Unsur alternasi seperti ini dapat dirasakan terutama pada pilihan suasana, baik itu suana resmi, serius, dan kadang-kadang digunakan untuk transisi suasana dari tegang ke suana akrab, dan bahkan santai.

Kombinasi ragam bahasa ini muncul dalam teks, yaitu pada adegan Anoman dan Irawan pada saat perjalanan ke kerajaan As- 
tina untuk menculik Diah Lismaya Wati. Mereka diiringi oleh dua panakawannya, yaitu Tualen dan Merdah. Dalam adegan ini suasana tegang muncul pada saat Anoman terbang, naik turun sehingga membuat Tualen ketakutan. Tualen menyarankan Anoman agar terbang dengan penuh hati-hati, kalau tidak nanti bisa menabrak pohon. Merdah yang kerdil, tidak takut dengan ketinggian menyarankan ayahnya untuk berpegangan dengan erat supaya tidak jatuh. Dalam adegan ini juga nampak rimbunnya pepohonan di hutan yang mereka lintasi. Tualen dan Merdah terkesima melihat keasrian alam dengan masih banyaknya pepohonan rindang tinggi menjulang. Berikut kutipan dialognya seperti di bawah ini.

Tualen : Kanggeang alon-alon masih kal rauh derike. Yan mekeber aratu ngebut, punyan kayu bakat tomplok di duwur.

Anoman: Bahhh yogya, yan mangkana ngiring. Nda ta, katon-katon ikanang taru marikanang sor.

Merdah : Nanang tepuk to kayune beten?

Tualen : Alas beten to dah.

Tualen :Duhh punyan kayune beten, ane di sisi tukade mererod rumasa ia masuluh nguntul. (kaset I, side A, 87-98)

Dialog di atas menunjukkan bahwa Tualen yang seharusnya menggunakan bahasa resmi saat berbicara dengan Anoman, tetapi pada adegan ini ia memakai bahasa tidak resmi karena situasinya tidak formal. Seperti kata "Kanggeang alon-alon masih kal rauh derike. Yan mekeber aratu ngebut, punyan kayu bakat tomplok di duwur"; bahkan tidak juga menggunakan bahasa Bali Alus. Dalam dialog ini pun, Merdah juga ikut berdialog dengan menggunakan bahasa tidak resmi sebagaimana dalam dialognya "duhh punyan kayune beten, ane di sisi tukade mererod rumasa ia masuluh nguntul'.

Ragam bahasa tidak resmi ini juga digunakan dalam dialog tokoh kiri, yakni dialog Delem dengan Sangut berikut.

Delem : Maan dowen Kresna ne ngelonin. Apa ye baang sujatine to ngut?
Sangut: Bahhh cang sing nawang. Melem matur kemu nake. Napi aturine aratu dados sareng keto abete.

Delem : Peta gen cai. Yen tepukina ken Bima dong sing kemplangina bin kaka.

Sangut:Sing ja kenken, kewale ingetang nengkikin dowen. (kaset III, side B, 1072-1075)

Kutipan di atas merupakan adegan serius, akan tetapi dibawakan dengan dialog santai. Sebelum dialog di atas, terlebih dahulu terjadi pertempuran antara sang Kala Nila Ludraka dengan Kresna. Seperti pada kalimat "sing ja kenken, kewale ingetang nengkikin dowen" yang artinya Sangut menyuruh Delem untuk menggertak Bima, tetapi suruhan itu hanya sebagi candaan saja, sehingga nampak suasana akrabnya. Dalam pertempuran itu, Sang kala Nila Ludraka kalah. Setelah itu Delem dan Sangut membahas kelicikan dari Kresna dengan bahasa ragam akrab. Dengan demikian dialog gaya alternasi ragam resmi dan ragam akrab bisa ditunjukan contohcontohnya seperti yang terdapat pada naskah Lakon Irawan Rabi dalam WKP dalang Rai Mesi.

c) Alternasi timur bertembang dan tutur gancaran

Alternasi jenis bertembang dan tutur gancaran adalah penggunaan tutur bertembang dan tutur bukan bertembang (disebut gancaran) secara berselang-seling. Biasanya dapat dijumpai pada tokoh panakawan yang memanfaatkan jenis kakawin, atau jenis tembang lain sebagai media bertuturnya. Dalam kakawin ada kalimat yang berisi tentang arti dari tembang yang telah diucapkan. Kalimat itu, disebut sebagai tutur gancaran. Dalam teks Lakon Irawan Rabi ini banyak ditemukan bentuk tutur ki dalang yang menggunakan gaya alternasi jenis ini. Kutipan berikut merupakan contoh salah satu adegan yang memuat tutur bergaya alternasi bertembang dan tutur gancaran.

Tualen: Gending ngelemesin anak luh asapuniki. Pengorengan gede ratu titiang.

Irawan : Pengorengan gede? 
Tualen: Inggih, uling pidan nyambangan. Pengorengan gede jambangan.

Tualen : Mangkana Tualen

"Begitulah Tualen"

Tualen : Inggih. Crocot tanah ban nyaratang, yoka sleteban ngulati, kedis petenge ya mamunyi, mara jani ye ketepuk. kedis peteng celepuk. Sampaian pesel dong gelisang. lis nika sampian pesel. Sampin jambul dong tulungin, apang payu, ma don jaka makaronan.

Irawan : Mangkana Tualen. "Begitulan Tualen"

Tualen: Inggih, bebek katih ratu titiang, sebilang peteng krarak-kririk, manahe macedok tirta.ngulantingin ratu mas manik, juan bunga ya makilit, untun sampi ya ngatekul, iratu masubak kelian, kayune maseh asesai. Yan subak kelian punika pekaseh. Belakas jantuk sampunang je ngulen pasah. (kaset II, Side A, 390-396)

Dialog di atas terjadi pada adegan Irawan sudah masuk di Astina, di tempat tinggal Diah Lismaya Wati. Tualen memberikan lagu yang biasanya digunakan untuk merayu wanita, yang kemudian disambung dengan gancaran untuk menjelaskan isi tembang.

d) Alternasi irama

Suatu teks (naskah) lakon yang menggunakan bahasa sebagai media ungkapnya pasti memiliki unsur irama. Begitu pula dalam Lakon Irawan Rabi, jenis alternasi irama nampak jelas. Sutan Takdir (Periksa Rota, 1990: 1993) mensinyalir adanya tiga jenis irama dalam bahasa Indonesia, yaitu irama panjang-pendek, irama tinggi-rendah dan irama keras-lemah. Irama tinggih-rendah, dan irama keras-lemah tidak diuraikan, karena pengungkapannya harus dengan kata-kata dari hasil mendengarkan rekaman. Di antara ketiga jenis irama tersebut ada perbedaanya. Irama tinggi beralternasi dengan irama rendah, irama keras beralternasi dengan irama lemah. Hal ini dapat dilihat pada tokoh Delem yang bersuara keras, beralternasi dengan suara Sangut yang berirama lemah. Begitu pula suara Irawan pada saat petangkilan berirama tinggi, dengan suara Tualen yang berirama rendah. Jika terjadi pertemuan dialog antara tokoh-tokoh tersebut akan dirasakan adanya alternasi dalam irama dialog mereka.

Dalam Lakon Irawan Rabi jenis irama panjang-pendek dan irama tinggih rendah terdapat pada babak II, yaitu dialog Tualen dengan Condong dalam adegan pertemuan antara Irawan dengan Diah Lismaya Wati. Berikut kutipan dialog yang dimaksud.

Tualen : Yen dadi kepala wanita tawang arti wanitane?

Condong: Napi punika arti wanitane?

Tualen : Wanita, wani: berani, ta:taat. Wanita adalah berani membe diri demi kebenaran, taat kepada nasehat orang tua ibu dan bapak. To artin wanitane pang tawang nyai. Yen dadi wanita orine ja. Gumine melakar uli panca sila. Tata susila wanita tingkah wanita masih lelima dasarne.

Condong: Napi punika? (kaset seri:II, side A, 483-486)

Kutipan dialog di atas mengilustrasikan Tualen memberi wejangan kepada Condong karena tidak bisa bertingkah laku yang baik sebagai kepala wanita. Seperti kalimat Wanita, wani: berani, ta:taat. Arti istilah wanita adalah berani membela diri demi kebenaran, taat kepada nasihat ibu dan bapak. Tualen memberikan arti wanita dengan irama panjang-pendek. Pada saat kedua tokoh panakawan itu berbicara, maka tampak alternasi irama tinggi-rendah. Suara tinggi terdapat pada tokoh Condong, sedangkan suara rendah terdapat pada tokoh Tualen.

Selain itu terdapat pula alternasi irama keras dan lemah atau halus. Jenis alternasi irama seperti ini biasanya terdapat dalam dialog Delem dengan Sangut. Berikut kutipan dialog tersebut.

Delem : Aluh, misalne yen kal metakon cai kal luas kija, anggo be you ne to. You was kij?

Sangut: Adi ade bahasa Inggris soleh. Ape artine to?

Delem : Men you kamu, was luwas, kij kije.

Sangut: Bahh yen keto aluh cang bisa masi 
bahasa inggris. Cang Ine jemak cang. I bi das lig tor.

Delem : Apa artine to?

Sangut: I:saya, bi: dibi, das: das, lig: lilig, tor: motor. Saya das lilig motor. (kaset II, side A, 231-237)

Pada kutipan di atas bahasa Inggris digunakan sebagai bahasa plesetan seperti kata You was kij? Yang berarti kamu pergi ke mana. Irama yang dipakai dalam dialog ini ada dua yaitu irama keras-halus, dan irama panjang pendek. Suara Delem yang keras dibandingkan dengan suara Sangut yang lirih halus adalah jenis irama keras-halus. Sedangkan kata plesetan yang dituturkan oleh Delem seperi I: saya, bi: dibi, das: das, lig: lilig, tor: motor. Saya das lilig motor adalah alternasi dengan irama panjang-pendek.

\section{Epentesis}

Kata epentesis dalam kamus besar bahasa Indonesia artinya penambahan huruf ke dalam suatu kata terutama kata pinjaman tanpa mengubah arti untuk menyesuaikan pola phonologis (bunyi-bunyi menurut fungsinya) bahasa peminjamnya. Jika dikaitkan dengan naskah lakon, berarti penyisipan bahasa lain ke dalam bahasa dialog yang digunakan. Misalnya dialog berbahasa Bali diselipkan kata, kelompok kata, atau kalimat berbahasa Indonesia bahkan bahasa asing. Atau dalam dialog memakai bahasa Kawi disisipkan kata, kelompok kata atau kalimat berbahasa Bali.

Penyisipan bahasa lain dalam Lakon Irawan Rabi ini nampak pada awal babak kedua yaitu adegan pertama dialog Delem dan Sangut. Dalam adegan ini, Sangut yang lebih dominan menguasai bahasa-bahasa luar daerah Bali, sedangkan Delem yang sombong hanya mendengarkan tanpa mau mempelajarinya. Berikut ini adalah kutipan dialog Delem dengan Sangut dalam Lakon Irawan Rabi.

Delem : Mabet-mabet bisa cai. Yen ade tamu uli jawa?

Sangut : Monggo mas. Pajenengan pade tindak pundi.

Delem : Pajenengan engken je?

Sangut: Badah melem sing nawang, monggo kinarah rumihin. Saudara mau kumana, mari mampir dulu.

Delem : Jawa to, Madura engken?

Sangut: Kula ledang cileng medur, apek kono apek kalakok ingte. Saya ini orang madura tapi sudah lama kerja disini. Engki ring sura boja neka.

Delem : Bahhh jeg sing kene baan ngartiang to.

Sangut: Yen omong Makasar len. dalasiah mele be kedek, lebalandia wa suwe aku ora not cicing not bang sido, nek bang duang aku kenali bang sido. Sangkang menuh sida lemanampana. E akama kamane amotra jam siapa ne ae, ma kiandre kena mi.

Delem : Omong apa to?

Sangut: Makasar to, pang tawang melem yen Sunda bin len. Kua juragan bade angkat kemanten.

Delem : Misi juragan pere. (kaset I, side B, 184-202)

Kata-kata, kumpulan kata dan kalimat di atas adalah sisipan bahasa lain, seperti kalimat kula ledang cileng medur, apek kono apek kalakok ingte merupakan bahasa Madura yang artinya saya orang Madura tapi sudah lama kerja di sini. Selain bahasa Indonesia dan bahasa daerah lain, terdapat pula sisipan bahasa Inggris dalam naskah Lakon Irawan Rabi ini. Kutipan dialognya seperti di bawah ini:

Delem : Kaka len, ade jeg bahasa inggris. To jeg pipis ngecor. Kewale bisa basa inggris, ade tamu luar negeri, sape to dadi gaid.

Sangut: Engken abete?

Delem : Hallo mister, tawang cai apa. The time is many, waktu adalah uang.

Sangut: Nang ajahin cang bahasa Inggris, sing keweh?

Delem : Aluh.

Sangut: Aluh engken je.

Delem : You kamu, I saya. To duen apalang ken no bin besik.

Sangut: Yen nakonin timpal

Delem : Aluh, misalne yen kal metakon cai kal luas kija, anggo be you ne to. You was kij? 
Sangut: Adi ade bahasa Inggris soleh. Ape artine to?

Delem : Men you kamu, was luwas, kij: kije. (kaset I, side B, menit 50.36- 51.02)

Penggunaan bahasa Inggris dalam $\mathrm{La}$ kon Irawan Rabi, nampak pada kata-kata yang diungkapkan oleh tokoh Delem dan Sangut. Bahasa Inggris ini lebih banyak digunakan sebagai bahasa plesetan seperti You was kij (kamu pergi ke mana). Kalimat ini sesungguhnya adalah bahasa Bali yang dibawa ke dalam bahasa Inggris, sehingga menjadi bahasa plesetan. Selain itu ditemukan pula penyisipan bahasa Bali di tengah-tengah rangkaian bahasa kawi yang dipakai sebagai dialog, seperti pada kutipan di bawah ini. Werkodara: Yah kadiang punapa mangke. Ingulun aminta mulih tan pawehan, sedurung manya ikanang karya. Tatan weruh aku paling sing bisa ajaka jangkak-jongkok kene. Enggalan tujune pesu yen jagkak jongkok. Nagih mulih yen konden pragata gae sampunang budal. Samangkana saturan ira sang satus Korawa, aku mesem lawan kaka yudistira. (kaset II, side A, 297)

Kata, kelompok kata, dan kalimatkalimat di atas adalah bentuk-bentuk sisipan pada rangkaian kalimat dalam dialog. Dialog Bima "Tatan weruh aku paling sing bisa ajaka jangkak-jongkok kene, Enggalan tujune pesu yen jagkak jongkok" menunjukkan adanya penyisipan bahasa Bali dalam bahasa kawi. Kombinasi bahasa demikian diperbolehkan dalam tradisi wayang Bali apabila didasarkan pada watak tokohnya. Oleh karena Bima memiliki watak kasar, maka ia diperbolehkan menggunakan bahasa Bali. Apalagi pada saat marah, maka penyisipan bahasa Bali dalam bahasa kawi akan semakin nampak.

\section{Repetisi}

Repetisi atau perulangan bunyi sering dilakukan oleh seorang dalang. Keraf (1985:127) menyatakan repetisi adalah perulangan bunyi, suku kata atau bagian kalimat yang dianggap penting untuk memberi tekanan dalam sebuah konteks yang sesuai. Gaya repetisi juga terdapat dalam Lakon Irawan Rabi. Berikut adalah kutipan tutur bergaya repetisi:

Tualen : (pengalang) Sawur ira tan apanjang, singgih sang nguniwara ulun yeki, ketalian dening bakti lawan asih. Uduhbh aratu dewa agung, mamitang lugra tityang parekan ituwa, matur tityang ring buk padan palungguh aratu, aratu sareng sami sane iring tityang sewewengkoning sabe mendala pandawa, pinih ribin aratu pangobaktin tityang katur ring palungguh aratu sareng sami mangdene sampun itua kecawaking ila kadi mangkin. Nunas lugra

Anoman: Ngadeg.... tualen kalaganta ya ta warian wus asung kerta lugraha juga lawan sira bayu temaja, mulih ring hyang-hyangin sinembah kalawan kita tualen. (kaset I, side A, 10-11)

Kutipan dialog di atas merupakan penggambaran suasana adegan petangkilan di Indraprasta antara Anoman dengan Irawan diiringi oleh Tualen dan Merdah. Pengulangan kata aratu dalam dialog di atas, sebenarnya tidak mempengaruhi arti kalimat yang dituturkan, melainkan digunakan sebagai kata penegas. Contoh lain dari gaya repetisi yang terdapat pada naskan Lakon Irawan Rabi adalah sebagai berikut.

Baru : Lakar mesiram masih maweda. Paling keweh dadi peranda, mekikihan merayunan memantra, mekikihan sirep masih memantra. Keto yen ngelarang kedarman, iraga dadi parekan sing misi keto,yen sube seduk, jemak jeg tekor. Eee niki tekorang, jangin jukut beres. (tokoh baru keluar, kemudian masuk lagi) Irage diapin sing nawang weda, bagian nyanyinyanyi liyu tawang. yen ade lagu alitalite jani dingeh cepok jeg kene ben. (bernyanyi) sane dibi titiang tumben ke kota ke toko baru manumbas kaca mata, ade teka dong iya uli kajoo. (kaset II, side A, 314) 
Dialog di atas adalah ungkapan tutur tokoh Baru yang menjelaskan kegiatan sehari-hari seorang sulinggih. Baru selalu meng ulang kata makikihan dan mamantra merupakan upaya sang penutur untuk penekanan terhadap pentingnya mantra dalam kehidupan sehari-hari, yakni: seorang sulinggih, sebelum mandi harus mengucapkan mantra, sebelum makan juga mengucapkan mantra.

\section{Koreksio}

Gaya koreksio biasanya dipakai oleh seorang dalang saat dialog panakawan. Salah seorang panakawan yang sering mengucapkan kata-kata yang salah, baik itu secara disengaja maupun tidak (pikun). Salah ucapan tersebut diperbaiki sendiri ataupun diperbaiki oleh lawan bicaranya. Gaya tutur ini disebut dengan gaya koreksio. Berikut contoh-contoh kutipan dialog dalam Lakon Irawan Rabi.

Delem : Atuta yan tonian yatna ring niti kabelasah ikang caru suksemeng tri loka.

Sangut: Tri... kola

Delem : Tri kola apa... triiiiiii loka. Loka

Sangut: Lokalo. (kaset I, side B, 117-120

Kata "Tri Loka" berarti tiga dunia. Namun demikian Sangut dalam mengucapkannya disalahkan menjadi "Tri Kola". Kemudian Delem mengkoreksi ucapan Sangut. Kata tri kola yang diucapkan Sangut sebenarnya tidak mempunyai arti, akan tetapi seorang dalang menempatkan sebagai media untuk memunculkan perbedaan pendapat di antara keduanya. Kalimat-kalimat atau kata-kata pada kutipan diatas, menjadi indikator yang membuat tutur dalam dialog panakawan Lakon Irawan Rabi dalam WKP oleh dalang Rai Mesi mengandung tutur bergaya koreksio.

\section{Mempertegas}

Dialogpanakawanseringkalimengulang pembahasan tutur yang telah diucapkan pada adegan sebelumnya oleh tokoh para ratu. Gaya seperti ini disebut dengan gaya mempertegas, karena tutur berbahasa kawi sulit dimengerti oleh penonton, sehingga membutuhkan penjelasan, agar dapat dipahami kepastiannya. Misalnya pada Lakon Irawan Rabi, setelah adegan sidang di Indraprasta, pada saat terjadi konflik antara Tualen dan Merdah. Merasa dirinya sudah tua, Tualen sebenarnya tidak ingin menikah lagi, tapi karena ada unsur paksaan dari Anoman dan Merdah, akhirnya Tualen bersedia untuk pergi ke Astina mencari panyeroan Diah Lismaya Wati. Kutipan berikut merupakan dialog yang dimaksud. Tualen : Nden malum, de jeg ulah ngiring. Merdah: Ape ne beratang nanang?

Tualen : Ane beratang nanang, sing dingeh cai bawos ida sang Irawan ngenikayang jani karya ditu mekejang watekin Pandawa miwah para ratu, ne sakti ngaturan ngaksi karyane ditu. Panjak-panjak sinah mekejang ngayah, ade maebat, ade megorengan. To jani lantas nanang ajak cai ngiring dane sang Anoman muang sang Irawan ngemaling kemu. Yen tawange lantas, ketare ditu sinah runtuh kawibawan sang Panca pandawane kaden keto. Buine yen tawange teken tukang ebate, badah jeg uwug, maling...jeg talenan ape menek, blakas menek. Ane jejehin nanag lengis umbane ane kebus ento.

Merdah: Engken ne nang.

Tualen : Anak masan ngoreng umbe ditu, temblage tendase aji lengis umba. Si jeg prejani menek pangkat nanang, koplar. (kaset seri: I, side A, 44-50).

Dalam adegan ini, sesungguhnya Tualen mengulang kembali ucapan Irawan yang sudah dituturkan sebelumnya. Kalimat mempertegas yang dimaksud seperti kata "sang Irawan ngenikayang jani karya ditu mekejang watekin Pandawa miwah para ratu, ne sakti ngaturan ngaksi karyane ditu." Kalimat tadi merupakan pengulangan kata sang Irawan pada adegan petangkilan. Maka tutur di atas dapat dikatakan sebagai tutur mempertegas. Gaya mempertegas juga terdapat pada babak ke II saat Irawan sudah berhasil di bawa ke Astina untuk diserahkan kepada sang Kala Nila Ludraka. Pada adegan ini, Delem mempertegas bahwa maling sedang disiksa oleh Bima. Adegan penyiksaan tersebut sudah terjadi pada 
adegan sebelumnya, akan tetapi Delem menegaskan kembali dengan tutur. Dengan demikian gaya bertutur mempertegas, dapat ditemukan dalam Lakon Irawan Rabi.

\section{Kontradiksio}

Pertentangan antara dua keadaan atau sesuatu yang mempunyai perbedaan mencolok disebut dengan kontradiksi. Peristiwa, situasi, atau kondisi yang melukiskan bertentangan biasanya ditemukan pada dialog panakawan, terutama dialog Delem dan sangut pada Lakon Irawan Rabi. Namun demikian terdapat pula dialog yang bertentangan antara dua tokoh ratu, seperti ditunjukkan dalam dialogp ada babak pertama adegan sidang berikut.

Irawan : Pakulun..... sira paman inganika, kesamakna juga ritekap sirang Irawan. Apan yeki kari rare winguda urung antes angamet, angalap, ikanang pria. Mangkana sira paman. Riwekas juga, yan aminta sib ri kunang paman inganika.

Anoman : Hihibihi... pradnyan kita warah aken awaknya kari rare. I anoman sampun angelaraken aji waskita, wruh lawan wredayan ta. Kita mangke sampun antesangamet ikanang priya. Sang apa ingantekaken lawan ta kita, I Abimanyu sampun angamet ikanang stri, I gatot kaca sampun juga angamet ikanang stri. Kita kewale durung. Menawa kita sengsaya ri yayah ta arjuna. Yan kroda Arjuna, anoman tadahe ikanang baya. Yan kroda wrekodara, anoman tadahe ikanang baya. (kaset I, side A, 3943)

Dialog di atas menunjukkan Anoman mengetahui bahwa Irawan dalam hatinya memendam perasaan cinta kepada Diah Lismaya Wati. Untuk itu Anoman menyuruh keduanya untuk menikah dengan cara apa pun. Namun Irawan menolaknya dengan alasan bahwa dirinya masih terlalu muda, selain itu Diah Lismaya Wati sudah akan menikah dengan Sang Kala Nila Ludraka. Selain terdapat dalam tutur dialog konflik, tutur bergaya kontradiksio terdapat pula dalam adegan formal atau sidang.

\section{Kias-banding}

Untuk memperkuat dialog dan membandingkan sifat, keadaan, dan perilakunya dengan tepat dan jitu biasanya ki dalang menggunakan gaya kiasan. Purnamawati (1997: 31) mengatakan bahwa penggunaan gaya kiasan selalu menggunakan pertimbangan, baik dari atribut manusia terhadap obyek-obyek maupun ide-ide yang tak bernyawa. Bila menyatakan kekaguman terhadap obyek yang dilihat, sering dipakai suatu ungkapan abstraksi atau pengandaian. Jadi penggunaan bahasa kiasan adalah salah satu cara penyampaian pikiran dan perasaan seseorang terhadap orang lain, sehingga penuh rasa keindahan ada di dalamnya.

Dalam Lakon Irawan Rabi dijumpai pula jenis tutur ini, yaitu pada saat Irawan dan Tualen sudah berhasil masuk di kediaman Diah Lismaya Wati, seperti dalam kutipan dialog berikut.

Tualen: Ugase malu tiang ngelemesin anak luh nak pragat aji gendingan, sesawangan, sing keto ngayahang malu, patut matekap nulungin matwane. Sing keto cara jani behh nyaru-nyaru mebalih televisi jeg saget sube gandengan. Dumun tiang sampun ping tiga pocol ngayahang atiban-atiban nika.

Irawan : Mangkana tualen?

Tualen : Inggih, sangkal wenten anak ngorang kempul barong di menguwi, bubul baong ningeh munyi.yen malu ngelemesin anak luh ngange gending aratu. (kaset II, side A, 386-388)

Ungkapan kempul barong di menguwi, bubul baong ningeh munyi adalah kiasan yang digunakan menggambarkan sesuatu yang sangat tidak mengenakkan. Seperti saat tenggorokan Tualen sedang sakit, ia memaksa diri untuk melantunkan lagu rayuan. Oleh karena itu suaranya sangat tidak enak sehingga rayuan tidak mempan, tetapi malah kemarahan yang diperolehnya. Kata kiasan dapat dijumpai pada adegan lain dalam Lakon Irawan Rabi. 


\section{Penekanan (stressing)}

Sebagaimana yang berlaku dalam dialog wayang kulit Bali, baik itu tokoh ratu atau pun panakawan, Lakon Irawan Rabi ini pun menggunakan penekanan pada akhir kalimat. Penekanan pertama mengandung unsur tantangan, sedangkan penekanan kedua mengandung unsur respon. Katakata penekanan yang dimaksud adalah (1) yogya-patut; (2) boya ja kenten-yogya; (3)sing keto-ae; (4) sing keto-saja, dan sebagainya. Tutur seperti ini disebut dengan tutur penekanan. Kata yogya-patut digunakan sebagai penekanan kalimat sebelumnya bahwa kalimat yang diucapkan adalah suatu kebenaran dan patut dilaksanakan. Sebelum Anoman mengatakan yogya, terlebih dahulu Tualen mengartikan ucapan Anoman. Setelah itu, kemudian Tualen mengatakan inggih patut. Artinya bahwa ucapan sebelumnya perlu ikuti dan dilaksanakan.

\section{b. Sor-singgih}

Bahasa Bali adalah bahasa ibu yang menjadi media komunikasi dalam kegiatan bertutur masyarakat Bali. Adanya konsep catur warna (brahmana, satria, waisya, dan sudra) membuat tingkatan-tingkatan dalam berbahasa yang disebut dengan sor-singgih basa atau unda usuk basa. Poedjosoedarmo (dalam Rota, 1990: 237) mengatakan dalam bahasa Bali memiliki tingkatan yang cukup komplek, bervariasi serta perbedaan antara bahasa satu dengan yang lainnya ditentukan oleh perbedaan sikap santun yang ada pada diri pembicara terhadap lawan bicara.

Begitu pula dalam kesenian wayang, konsep ini masih berlaku, khususnya pada Lakon Irawan Rabi, dimana perbedaan kedudukan sangat tampak antara kedudukan Irawan sebagai junjungan, dengan Tualen sebagai parekan. Saat berdialog, Tualen harus menggunakan bahasa Bali alus sor. Bahasa ini disebut bahasa vertikal, seperti pada kutipan dilaog di bawah ini.

Irawan : Pakulun....sira paman inganika, kesamakna juga ritekap sirang Irawan. Apan yeki kari rare winguda urung antes angamet, angalap, ikanang pria. Mangkana sira paman. Riwekas juga, yan aminta sib ri kunang paman inganika.
Tualen: Nawegang titiang ring palungguh iwa, sapunika ida i anak. Amangkinan durung wenten manah titiang jagi ngerereh somah. Malih pidan yan sampun antes titiang pacang ngerereh timpal wiadian somah, irika wenten atur titiang ring palungguh iwa. Taler iwa jagi tunasin titiang pisarat. Asapunika mangkin nawegang titiang. Apin cai merdah, lek ati nanang, gigi suba pawah bin nganten. (kaset seri: I, side A, 39-40)

Tualen memberikan saran kepada Irawan untuk tidak mengindahkan permintaan Anoman dengan alasan usia Irawan masih terlalu muda, menikah dengan cara mencuri tidak baik, perilaku seperti itu akan mempermalukan orang tua, dan sebagainya. Dalam kondisi seperti ini tokoh panakawan harus menggunakan bahasa Bali alus. Jika situasinya terjadi antar tokoh panakawan, maka bahasa Bali kasar lebih dominan. Seperti pada kutipan dialog Delem dan Sangut berikut ini:

Sangut: Engkenange lem?

Delem : Beorang sepanan nepis. Saget sube gidate kene. Sing medaya kala nyagur sang Bima. Mula biasa sang Bima keto, mekebyeng kunang-kunang bene. Tamyu nomor 1 paling nakale. Nyanan kal aturen kopi adukin aon.

Sangut: Nyenn? Sang bima?

Delem : Ae, alus aturkakane, "nawegang aratu malinggih dumun" keto. Jeg nyen kal perintah keto nikan ida. Suba barak biing muane, kaka megedi ugas to.

Sangut: Yen melem melaib, jeg akecosan bakatange ken sang Bima. Cang bani sing matur ken sang Bima luwungan ane lenan je aturin lem. (kaset II, side A, 322-329)

Nampak jelas kondisi dialog pada adegan ini adalah level horizontal, artinya penutur dalam kondisi dan kedudukan yang sama dan pergaulan akrab, sehingga bahasa yang digunakan dalam dialog adalah bahasa Bali kasar. Selain jenis dialog di atas, terdapat dialog antar panakawan dengan tokoh yang dimuliakan dengan menggunakan bahasa Bali kasar, dicampur dengan basa Bali alus singgih. 
Berikut kutipan tutur yang dimaksud.

Sangut: Sambeh, to be care tain kambing, ye mara tiwakina senjata ken ida sang Kresna. Usan mapuja mantra, ngelarang weda, tiwakange senjatan idane, yehhhh sambeh cara tain kambing pebresbres. (kaset III, side B: 1060)

Kata, kumpulan kata, dan kalimat yang dituturkan oleh tokoh Sangut adalah basa Bali alus yang dipakai dalam dialog panakawan. Topik pembicaraannya adalah menceritakan peristiwa dalam babak ketiga, yaitu pada saat adegan perang. Kalimat ye mara tiwakina senjata ken ida sang Kresna. Usan mapuja mantra, ngelarang weda, tiwakange senjatan idane, yehhhh sambeh cara tain kambing pebresbres adalah pernyataan Sangut untuk mengagungkan kesaktian yang dimiliki oleh Kresna. Bahasa jenis ini kerap disebut sebagai bahasa VertikalHorzontal, artinya satu dialog terdapat basa Bali Kasar dan basa Bali alus.

c. Narasi

Pada Penyacah Parwa, dalang memaparkan pokok cerita yaitu pertemuan antara Anoman dan Irawan di puri para Pandawa untuk membicarakan pernikahan Irawan. Narasi jenis ini disebut dengan narasi struktural menurut Zurbuchen. Yang dimaksud dengan narasi struktural oleh Zurbuchen (dalam Rota: 1990: 250) adalah pengalang, yaitu suatu tutur ki dalang untuk adegan pembuka dalam mengawali percakapan. Pengalang yang ditemukan dalam Lakon Irawan Rabi adalah sebagai berikut:

"Senduk samita natan katon ikang wredayeng hati. Ritatkala ineleh tan hanaleh angideaken manya tan kahedeh nriyaaken kang kwadaritusta, manah ira kaya sapa, ling ira sang asung asemida rikalaning sira bayu temaja, kanggek marewenten ikanang Indraprasta tinangkilalawan sira Irawan, tansah kewale umeneng juga".

Kutipan di atas menggambarkan adanya kesedihan pada salah satu tokoh yang diajak sebagai lawan bertutur yaitu Irawan, yang memendam perasaan cintanya kepada Diah Lismaya Wati. Jika penyacah mempunyai fungsi sebagai prolog yang mengantarkan keseluruhan lakon, maka pengalang berfungsi sebagai pengantar dari adegan pembuka yang berwujud narasi dalam bentuk tembang. Selain narasi struktural ada pula narasi dramatik, yang proses terjadinya tergantung pada cerita yang memiliki hubungan logis dengan gerak atau unsur plot dengan adegan yang lain. Berikut contoh kutipan narasi dramatik dalam Lakon Irawan Rabi.

"Senduk samita natan katon ikang wredayeng hati. Ritatkala ineleh tan hanaleh angideaken manya tan kahedeh nriyaaken kang kwadaritusta, manah ira kaya sapa, ling ira sang asung asemida rikalaning sira bayu temaja, kanggek marewenten ikanang Indraprasta tinangkilalawan sira Irawan, tansah kewale umeneng juga".

Kutipan di atas menggambarkan adanya kesedihan pada salah satu tokoh yang diajak sebagai lawan bertutur yaitu Irawan, yang memendam perasaan cintanya kepada Diah Lismaya Wati. Jika penyacah mempunyai fungsi sebagai prolog yang mengantarkan keseluruhan lakon, maka pengalang berfungsi sebagai pengantar dari adegan pembuka yang berwujud narasi dalam bentuk tembang. Selain narasi struktural ada pula narasi dramatik, yang proses terjadinya tergantung pada cerita yang memiliki hubungan logis dengan gerak atau unsur plot dengan adegan yang lain. Berikut contoh kutipan narasi dramatik dalam Lakon Irawan Rabi.

Ariwauu, pade sampun alungguh tekap ikanang ira Irawan muang bayu suta, mangke atangkila tekaping caraka nira.

Umeneng, tan sida umojare tekapa ira Arjuna. Mijil ira maka waduan ira sang Kala Nila Ludraka

Neng akena rilampah ira Bayu Temaja muang Irawan muang caraka. Mangke kawinursita maring telengin Astina pura, mebet sahananing para ratu muah pertiya presama. Diah Lismaya Wati tan sah atawan-tawan tangis. watek ikanang para ratu juga angantekan lamakane labda karya.

Narasi seperti dikemukakan di atas, dipakai untuk mengawali tutur naratif sang dalang. Berbagai narasi yang digunakan seperti, lumaris (berangkatlah), ri sadekala samangkana (jika demikan maka), tan warnanen (tanpa 
pakan komponen utama dalam bertutur sedangkan komponen bentuk narasi dan tutur bertembang adalah komponen yang menopang bentuk tutur dialog. Bentuk tutur dialog ada yang berbahasa Bali, berbahasa kawi, bahasa Indonesia, bahasa Inggris, dan sebagainya.

Untuk membangun komposisi tutur, dalang Rai Mesi melalukan upaya-upaya agar bahasa yang dipergunakan efektif dalam sajian pertunjukan WKP-nya antara lain dengan (1) memilih materi bahasa; (2) menata materi bahasa; (3) memilih corak bahasa; (4) dan memilih gaya bahasa. Dari upaya tersebut, dapat dikatakan dalang Rai Mesi memiliki daya kreativitas yang tinggi dalam memilih dan menata bahasa dalam kegiatan bertuturnya. Dalang Rai Mesi banyak memanfaatkan bahasa-bahasa di luar daerah, seperti bahasa Jawa, Madura, Kupang, Sulawesi, dan sebagainya dalam kegiatan bertutur dialog panakawan.

Dalang Rai Mesi dalam Lakon Irawan Rabi menggunakan teknik penyajian tutur dengan (1) gaya alternasi; (2) gaya epentesis; (3) gaya repetisi; (4) gaya koreksio; (5) gaya kontradiksio; (6) gaya mempertegas; (7) gaya kias-banding; (8) gaya penekanan (stressing); (9) sor-singgih. Aspek-aspek retorika ini membangun komposisi tutur yang dipilih, dan ditata, sehingga menjadi satu kesatuan wujud kebahasaan yang utuh.

Fungsi retorika dalang Rai Mesi dalam Lakon Irawan Rabi adalah (1) sebagai perkenalan tokoh- tokoh yang terlibat dalam kegiatan bertutur; (2) menjelaskan struktur adegan dalam cerita; (3) menunjukan kekerabatan antar tokoh wayang yang terlibat dalam kegiatan bertutur; (4) meningkatkan kadar nilai estetis dalam bertutur sang dalang guna mempengaruhi penonton agar tetap menonton pergelaran wayang serta tertarik untuk membaca isi (pesan dan makna) cerita; (5) dipergunakan sebagai alat mempengaruhi penanggap tutur oleh penutur.

\section{Kepustakaan}

Keraf, Goris, 1981. Diksi dan Gaya Bahasa, Jakarta: PT Gramedia. 1985. Komposisi: Sebuah Pengantar Kemahiran Bahasa. Ende: Nusa Indah.

Kutha Ratna, Nyoman. 2009. Stalistika: Kajian Puitika Bahasa, Sastra dan Budaya. Yogyakarta: Pustaka Pelajar.

Purnamawati, Ni Diah. 1997. "Retorika dalam Pertunjukan Drama Gong Bintang Bali Timur Dengan Lakon Ni Luh Sukerti”. Denpasar: STSI Denpasar.

Rota, I Ketut. 1990. "Retorika Sebagai Ragam Bahasa Panggung dalam Pertunjukan Wayang Kulit Bali”. Denpasar: STSI Denpasar.

Wahyudi, Aris. 2012. Lakon Dewa Ruci:Cara Menjadi Jawa; Sebuah Analisis Strukturalisme Lévi-Strauss dalam Kajian Wayang. Yogyakarta: Bagaskara. 
diceritakan) pula ditemukan dalam Lakon Irawan Rabi.

\section{d. Tutur Bertembang}

Jika dilihat dalam pakem baku wayang kulit tradisi Bali, tutur bertembang adalah salah satu komponen yang menopang keberhasilan dialog. Tembang merupakan jenis tutur bersifat ilustratif untuk memperkaya serta meningkatkan unsur estetik dialog, terutama membangun suasana (mood) dramatik yang sedang berlaku. Berdasarkan hasil pengamatan penulis, dalam Lakon Irawan Rabi sesungguhnya banyak terdapat gaya penyajian dalam wujud tutur bertembang, seperti alas arum, pengalang, bebaturan dan lain-lain. Banyak di antaranya mengutip dari cuplikan-cuplikan kakawin dan tidak sedikit pula tanpa diketahui sumbernya. Berikut kutipan gaya tutur bertembang yang dimaksud.

\section{Tembang (kaset seri I, 1)}

Rahina tatas kemantian, humuni meredangga kala sangka gurnitantara.

Gumuruh ikang gubarbala samuha puja serurumuhun

Para ratu sampun ayas ngasasalin lumampah awan rata parimita.

Nrepati Yudistira perang muka,Bimasena, nakula arjuna plarumurug.

Rasa belah sang mahetala, penuh wangkang pariwak dedet kemurbak.

Pengalang (kaset I, 10)

Sawur ira tan apanjang, singgih sang nguniwara ulun yeki, ketalian dening bakti lawan asih.

Kakawin (Kaset 1, 98)

Rabiang alas,

kadi maha mangidot.

Tumungkul cayanya dening atinget-tinget.

Ya mawan rikang luwah.

Cecantungan (kaset I, 111)

biatitan sang aneng-aneng asrama sedeng angiwa diyana lawan semadi. Katambetan narendra musub ira tikeng sampurna wirya, sangkepan sang mantra mantri saha balabala, wanua lapad kapa bela. Mangkin rug wengi penglayangan ngusak-asik dedet kumaresah kadi osah meh swarga, yata akenian atindak-tindakan dening upaya sakti.
Sesawangan (kaset I, 140-142)

I luutung katulung tulun, metindak kadi tayung kapundung, wireh takut ia ulung, yen ulung batisne lung. Ikukur ya mesawur, gelur-gelur ia di duur. swarannyane sade ngawurmesawur. mapi mapi mapituturTuare inget teken lacur, gigis pelih nagih nyagur.

Sloka (kaset II, 3130

Om keswama-swamam sarwa dewa nugrahakem, yarnanem sarwa pujanam nama sarwa dewa nugrahakem.

Berbeda dengan kutipan di atas, penulis menemukan pula gaya bertembang yang beralternasi dengan dialog (gancaran). Berikut kutipan dialog yang dimaksud.

Sangut: Wetan kali kulon ya kali, ngareping nyebrang ka ono patih. Kene kadi konoya gati ne titimbang podo kaapti.

Delem : Aissss, gending apa to?

Sangut: Jowo!

Delem : Behhh, mabet-mabet nawang gending jowo. (kaset seri: 1, side B, 178-181)

Semua kata, kumpulan kata atau kalimat di atas adalah gaya tutur bertembang yang diucapkan secara berselang-seling oleh dalang melalui tokoh Delem dan Sangut. Dalam hal ini dialog tersebut tidak berupa terjemahan dari tutur bertembang, melainkan partisipan tutur memberikan respon, tanggapan atau reaksi terhadap tutur bertembang tersebut. Sangut bernyanyi dengan lirik Wetan kali kulon ya kali, ngareping nyebrang ka ono patih. Kene kadi kono ya gati ne titimbang podo kaapti, kemudian ditanggapi oleh Delem sebagai responden tutur dengan kata Aissss, gending apa to dan Behhh, mabet-mabet nawang gending jowo. Hal tersebut menunjukan bahwa setiap pernyataan salah satu tokoh harus direspon tokoh lain secara tepat.

\section{Penutup}

Dari pembicaraan di muka, kiranya dapat ditarik kesimpulan sebagai berikut. Aspek-aspek kebahasaan dalam WKP Lakon Irawan Rabi oleh dalang Rai Mesi meliputi bentuk-bentuk tutur dan cara yang digunakan dalam penyajian tuturnya. Bentuk-bentuk tutur yang digunakan dapat dibagi menjadi tiga yaitu dialog, narasi, dan tutur bertembang. Dari ketiga bentuk tersebut, dialog meru- 